Article

\title{
A Levinasian Reconstruction of the Political Significance of Vulnerability
}

\author{
Xin Mao \\ Department of Philosophy (Zhuhai), Sun Yat-sen University, Zhuhai 510275, China; maox3@mail.sysu.edu.cn \\ Received: 12 November 2018; Accepted: 24 December 2018; Published: 27 December 2018 \\ check for \\ updates
}

\begin{abstract}
The concept of vulnerability has been renewed in meaning and importance over recent decades. Scholars such as Judith Butler, Martha Fineman and Pamela Sue Anderson have endeavored to redeem vulnerability from its traditional signification as a negative individual condition, and to reveal the positive meaning of vulnerability as a transformative call for solidarity, equality and love. In this paper we examine the newly constructed positive understanding of vulnerability, and argue that the current way of pursuing this positive understanding affirms a merely functional positivity. In the recent accounts, vulnerability is still a status to avoid, yet functions positively as a corrective force to the environment that produces vulnerability. We will try to find an essential way of designating the positivity of vulnerability by revisiting the philosophical discussion on vulnerability in Emmanuel Levinas. We will argue that Levinas's notion of vulnerability is positive in a sense which goes beyond the purely functional; it is seen as essential for his definition of humanity. Yet compared to the contemporary discussion, Levinas's notion of vulnerability lacks a direct social political meaning. We will tentatively explore how the essential positivity drawn from Levinas can provide a new way to construct the political significance of vulnerability.
\end{abstract}

Keywords: vulnerability; functional positivity; essential positivity; ethical subjectivity; disruption

\section{Introduction}

The notion of vulnerability and its ethical alternative political implications have been the focus of discussion in recent decades. Judith Butler explores the notion of vulnerability through its importance for collective resilience (Butler et al. 2016). Martha Fineman develops her notion of dependency by reference to a more universal conception of vulnerability, which to her can be a "powerful conceptual tool" to address pervasive social inequality (Fineman 2008, p. 8). In her last works, Pamela Sue Anderson argued for a shift of discourse on vulnerability, breaking it away from a negative social imaginary, and recognizing vulnerability as a possibility for transformation. What their proposals have in common is a project to redeem the notion of vulnerability from a negative finiteness in the traditional discourse and explore its possible positivity. For them, the traditional discourse reveals a biased interpretation of vulnerability based especially upon the priority given to rationality and autonomy, while dismissing the importance of emotion, embodiment and relationality (Anderson, forthcoming). These scholars argue that it is essential to search for a way to counter the traditional approach and to envisage a new conception of vulnerability.

As Alexandra Timmer notes, these vulnerability theorists see vulnerability as "generative" or transformative (Timmer 2013), and as giving birth to a new ethics and better political systems. Vulnerability as a transformative status is no longer negative, but positively advances human affairs. Anderson maintains that vulnerability offers us more "positive possibility", as being wounded or lost makes us aware that "life counts when we are loved, or have been loved" (Anderson, forthcoming). Through this claimed positivity, vulnerability has become an important concept in recent social and 
political discussions. The shift from being purely negative to being positively celebrated redefines vulnerability and also opens up new theoretical possibilities. In this paper we offer a close examination of the positivity with which the notion of vulnerability has been denoted, yet also raise questions about this positivity, especially from the perspective of the work of Emmanuel Levinas. As long as the positivity of vulnerability remains only on a functional level-that is to say, although retaining an essentially negative status vulnerability acts as a corrective force with positive results-its separation from the traditional conception is not complete. Instead, we find in Levinas's notion of vulnerability the potential to make this separation complete. Levinas in his later works uses the notion of vulnerability together with newly reconstructed notions such as proximity, hostage and trauma. Some scholars consider that the language Levinas uses to depict vulnerability falls within the traditional negative approach: that of wounding and trauma (Murphy 2011). But if we look closely at his agenda and trajectory, we see that terms such as vulnerability, hostage, and wounding in fact denote something essential to defining us as human through ethical significance. Levinas claims that "previous to ... the capacity for being", that is the embodied vulnerability as weakness, "there is exposedness and vulnerability" (Levinas 1998b). This exposedness is precisely an ethical responsibility for the other which is the signification of being human (Levinas 1998b, p. 45). From this perspective, the positivity of Levinas's vulnerability is different from that in Butler or Fineman, as it is not a condition provoking caring or a tool towards a better political response, but rather an essential dimension of humanity. This essential positivity has not yet been properly discussed, but can offer an opportunity for the discourse on vulnerability to move on to the next level.

It also needs to be acknowledged that the Levinasian vulnerability was not assigned much political significance by Levinas himself, which can be seen as a shortcoming compared to the other scholars' conceptions. Indeed, from the beginning of this upsurge in interest in the notion of vulnerability, discussions on it have never been confined to purely philosophical terminological matters. Through their explorations of vulnerability, scholars show their concrete concerns for social ethics and political equality. For example, both Butler and Fineman point out the limitations of the liberal political system where the political subject is presupposed to be autonomic and self-interested (Fineman 2008; Butler et al. 2016). They argue for a more inclusive and egalitarian way of conducting politics through their emphasis on the importance of recognizing vulnerability for social policy changes (Butler et al. 2016). Fineman's direct appeal for a change in political legislation and a call for a responsive state shows a concrete approach to a generalized or universal vulnerability. In order to identify the relevance of Levinas's discussion to the other vulnerability theorists, we will bring Levinas's discussion into the frame of the political discussions on vulnerability. This will also shed light on the political importance of Levinas's philosophy from the perspective of the vulnerability discourse. There is a consensus among Levinas scholars that his philosophy has political importance (Morgan 2016; Cohen 2010; Caygill 2002; Alford 2004). The current exploration will demonstrate how this importance can open up the possibility of direct engagement with other contemporary important political debates.

\section{A Positive Notion of Vulnerability}

As Murphy points out, the vulnerability theorists who in the last decade have focused on the concept of vulnerability and theorized the human condition via it, needed to rescue the notion from its traditional and common usage as a purely negative condition or state. This shift of perspective firstly emerged within discussions of feminism. From a feminist point of view, the traditional way of seeing vulnerability as a status of feministic weakness and as a lack of capability is a "patriarchal myth" (Anderson, forthcoming). In the reasoning underpinning this connection, the feminist vulnerability theorists point out that the female is historically associated with embodiment and objects of desire. The female body is often seen as a passive existence which is vulnerable and "in need of active protection" (Butler et al. 2016, p. 2). Furthermore, the mind-body dualism and the priority given to reason over the body led to a domination of the body by the mind in the traditional discourse. 
The embodied female is at the same time claimed to be irrational. "Reason is constitutively male" (Alcoff 2000, p. 40), and females are emotional beings who are vulnerable to emotional disturbance: the female is said to be lacking rational control of her emotions. The historical division of labor between the genders and the lasting tradition of the female's social position as the dominated party enforce this theoretical bias. In this sense, vulnerability is negative because the feminine that is associated with it is a "second-class" citizen (Anderson, forthcoming, p. 7). Beyond the problem with vulnerability being traditionally a gendered notion, the vulnerability theorists also point out that the negative notion of vulnerability is closely related to identity politics. The less advantaged social groups are often labeled as vulnerable, which is also a way to marginalize and exclude some social groups from mainstream society (Fineman 2008).

Through their critique of the traditional negative way of seeing vulnerability, which reflects deep-rooted gender bias and social inequality, the vulnerability theorists aim at reconstructing the notion of vulnerability, and their first step is to address the presuppositions of the traditional negative views on vulnerability, and search for a positivity in vulnerability. Among them, Martha Fineman clearly poses a positive notion of vulnerability and in particular seeks a direct political application. For Fineman, vulnerability is seen as a negative status due to the particular association it has with social groups of certain identities. Vulnerability, she argues, is in fact a universal human condition in which the social subject constantly finds him/herself. It is important to examine this universal vulnerability, and accept the important truth that most incidents in life are beyond control. Fineman maintains that through analyzing vulnerability as a universal human condition, and countering the imagined liberal autonomic subject, one can uncover social inequality on a deeper level. The liberal political system based upon the autonomic political subject gives each person an ultimate sense of freedom, but also demands that each person take responsibility for their own fate. This approach creates a social-political atmosphere where dependency is hidden from public view, even though it prevails in real life. Through recognizing universal human vulnerability, the social structure is reconceived as inter-dependent and inter-related, where the citizens are "anchored at each end of their lives" (Fineman 2008, p. 12). By revealing the positivity of vulnerability as a universal human condition, Fineman promotes a "post-identity" politics where the state is responsive to each person's vulnerability without the need for specific labeling.

In this way, Fineman concludes, vulnerability should be seen as a positive "conceptual tool" (Fineman 2008, p. 9) to redefine the role of institutions concerned with creating better equality. Through uncovering our universal vulnerability, we could learn that "human beings need each other, and that we must structure our institutions in response to this fundamental human reality" (Fineman 2008, p. 12). This is to say that vulnerability is positive, in the sense that the deficiency of the current formal notion of equality can be revealed by recognizing the universality of vulnerability, helping to open a path towards genuine equality. Societal institutions will be structured for our universal vulnerability and be responsive to the constant need for protection. However, in closely examining the "positivity" of vulnerability in Fineman's discussion, it can be observed that this positivity is just functional, not essential. According to Fineman, vulnerability is a useful hermeneutic tool for better equality. This is to say, the attention directed to vulnerability and the analysis of it in political science and philosophy is helpful to improve the social-political system. But the notion of vulnerability itself is no different from the traditional one: it is still associated with poverty and discrimination, which is exactly a neediness for protection. Similarly, Butler argues that vulnerability is not an inactive victimizing status, but the very condition for resistance, which in fact constitutes "the very ground for modes of solidarity from below" (Butler 2016, p. 10). In other words, one should not stay inactively in vulnerability, but rather group with others and seek ways to resist it. In this sense, the very vulnerability itself is still a negative moment of a human being that calls for elimination.

This functional positivity given to vulnerability does not make a complete rupture with the traditional way of perceiving it. Even though vulnerability is given a positive outlook, it is still a bodily or social weakness. In its default presuppositions, vulnerability is some one's vulnerability, 
where the prototypal situation is that one person is vulnerable due to his/her bodily existence or exposure to violence and social inequality which calls for others' protection and care. In this sense, what vulnerability stands for is similar to what is put under critique, but the critics are demanding a shift of perspective in how we evaluate the result of vulnerability where vulnerability is not celebrated per se. For the subject who is vulnerable, the protection that is entailed by his/her vulnerability still seeks to eliminate the condition of vulnerability, even while recognizing that this vulnerability can never be vanquished once and for all.

This leads to the question, can one envisage a vulnerability that is essentially positive in itself? Vulnerability, an inclination to suffering, seems to be only passive. As we mentioned before, Levinas in his later works frequently engages with the notion of vulnerability, but his alternative and obscure designation of vulnerability puzzles his readers. Once in an invited talk to Dutch philosophers in Leyden, he was asked how vulnerability can lead to responsibility, as "if one suffers, one can no longer do anything" (Levinas 1998a, p. 83). Levinas answers by discerning vulnerability as "suffering for" from "suffering by", and explains that in the form of suffering by, vulnerability involves an individual positing him/herself for him/herself. This means that when we refer to one person suffering in a certain situation, we presuppose the center of the concern in the case to be the individual by him/herself. In this case, vulnerability is negative as suffering contradicts the movement of "for oneself". But when one discusses vulnerability as suffering for, the center of the concern shifts from the self for him/herself, towards the other and the movement "for the other". Suffering for is not an inactive status; it is passive only in the sense that the self is no longer ego-centric, who in fact actively moves towards the other and takes concrete responsibly for the other. This actively taking responsibility for the other is the essential positivity of vulnerability, where this status of being vulnerable so as to be responsible for the other defines humanity. In order to demonstrate this difficult yet groundbreaking idea, we will first trace in Levinas's writings the context of his reference to vulnerability and its significance.

\section{Vulnerability in Levinas}

Levinas's notion of vulnerability is certainly different from the traditional designation, but it also needs to be distinguished from the designation given by the mainstream vulnerability theorists. Especially from the perspective of the positivity of vulnerability, Levinasian vulnerability surpasses merely functional positivity and shows an essential positivity. It is positive not because it yields something good, but because it is Goodness itself.

To be precise, in Levinas's works, vulnerability in its various contexts has been more specifically associated respectively with feminine alterity or ethical subjectivity. In his early work Totality and Infinity, Levinas refers to the notions of frailty and vulnerability in his discussion of feminine alterity in the controversial section "phenomenology of Eros". Many feminist commentators criticize Levinas's separation between relationship of ethics and relationship of Eros in Levinas. For them, the feminine is not given an equal ethical status as the masculine other and the ambiguity of the ethical status of Eros relation opens up the possibility of violence to the female sex in Eros. For example, Luce Irigaray maintains that even though Levinas has explored the meanings of caress through which he approaches the other sex, he still prioritizes the responsibilities "in the world of man-amongst-themselves". The feminine in Eros does not have a face and is described with animality, which shows that his philosophy "falls radically short of ethics"(Irigaray 1991, pp. 115-16). However, Clair Katz warns us that it is improper to equalize Eros and ethics in Levinas, as Eros does allow the selfish satisfaction of one's desire which leads to a mutual symmetrical enjoyment, and which is different from the asymmetrical relation of ethics. The violence that can happen to the vulnerability of the lover in Eros needs to be noted and avoided, yet we need to discern "sensual pleasure from ethics (Katz 2007, p. 343). We agree with Katz's analysis here and argue that for Levinas Eros is importantly an ambiguous relation between the subject and the other, which is a necessary step towards ethical encounter yet Eros itself is not an ethical relation yet. 
According to Katz, the sexual difference in Eros defies Parmenides's unity of the one, through which Eros demonstrates a relation to alterity that surpasses totality (Katz 2007, p. 335). To be exact, in the "Phenomenology of Eros", vulnerability of the feminine essentially separates her both from the categories of being and non-being. She is relieved from her "own weight of being" and in this sense is qualified as alterity as she is foreign to the world (Levinas 1969, p. 256). The feminine is designated as a certain "ultramateriality" of the tenderness which is the "not yet" that nourishes the future (Levinas 1969, p. 256). The vulnerable tenderness is different from an objective "body-thing" seen from a physiological perspective. According to the objective category, bodily vulnerability as a body thing is only countenanced with distance and indifference. In Eros, Levinas maintains that vulnerability is not added to a neutral body, but it is the non-distinguished sensibility of the other. With this vulnerability, the feminine other in her ambiguous status escapes any intention of grasp from the subject where the relation of Eros can be distinguished from a relationship of objectification and totalization.

For Levinas, vulnerability in the relation of Eros is essential because it is through the vulnerability of the feminine other that the relation of Eros transcends intentionality (Levinas 1969). Despite the relation of Eros not yet being an ethical relation, the vulnerability of the feminine other presupposes the possibility of an ethical relation. The secret relation between the lovers is fundamentally refractory to universalization. The relatedness or their shared sentiment is different from a common concept shared by two thinkers. The intimacy and inter-relatedness in this particular manner signifies the subjectivity in this relation as both "inward" and "inter-subjectively structured" (Levinas 1969, p. 265), which is developed into the subjectivity of substitution in Otherwise than Being or Beyond Essence.

In his later works, especially in Otherwise than Being or Beyond Essence, vulnerability makes a more frequent appearance, which however is only associated with subjectivity. According to Bernasconi, in Otherwise than Being or Beyond Essence, with his introduction of a lexicon that brings in 'striking' extremity, for example, 'hostage', 'persecution', Levinas offers a radical account of ethical subjectivity that develops from his previous work (Bernasconi 2002). Vulnerability is in fact part of these extreme terms utilized to describe the ethical subjectivity. To understand this vulnerability, first, one can observe that it is a certain exposure of the self to the other:

vulnerability, exposure to outrage, to wounding, passivity more passive than all patience, passivity of the accusative form, trauma of accusation suffered by a hostage to the point of persecution, implicating the identity of the hostage who substitutes himself for the others: all this is the self, a defecting or defeat of the ego's identity. (Levinas 1998b, p. 15)

Vulnerability as an exposure to the other puts the subject into a position wherein she/he cannot have any other choice but to open to the other, that is, to be responsible for the other before any ego-centered movement. Self-preservation seems to be denied to an incomprehensible level. But we need to pay attention to Levinas's methodology of depicting the vulnerable subject that exposes to the other. For Levinas, the ethical relation is not constituted by an ontological synchronization. Rather, it is a production of the process of overbidding. The original French term for overbidding is surenchère, which literally means overstatement. The method of overbidding is employed by Levinas to express a 'manner of overstating', 'hyperbole', and 'exasperation' (Levinas 1998a, p. 88). This method is opposed to the ontological way of posing an idea where every idea is reduced from a universalized being or concept. Through overbidding, one idea is overstated and expressed to its superlative level in order to reach the 'otherwise-than-being', which cannot be sought within the implication of being. In this sense, the extreme notion of vulnerability is not a description of a status of being, but an effort to reach towards "otherwise than being". The extremity of one's responsibility presupposes any concrete ethical principles and everyone's self-preservation. This extravagant responsibility guarantees that the vulnerable subject is vulnerable to the responsibility for the other before he/she is vulnerable for him/herself.

For Levinas, it is only when the subject does not posit him/herself for him/herself, and being a subject of "disinterestedness", that ethics could gain its firstness against violence and indifference. 
He bears witness to the fragility of ethics when ethics is presupposed by the self-centered subject who supposedly can easily make the right moral decision. Through advocating a vulnerable subject, Levinas locates the core problem of the savageness of human civilization: the individual as a social agency with self-interests first and foremost (Levinas 1998a). When the subject is established by self-affirmation, the world cannot avoid revenge or war. The self-interested movement is the undercurrent of any pretentions to a noble act which begins with the cogito. Levinas calls for an alteration of this world, and he argues that positing a subject who is vulnerable to being responsible for the others would orient us to this alternation. In this sense, vulnerability as being vulnerable to responsibility for our fellow human beings becomes a positive, even essentially positive human condition. This human condition for Levinas is the humanity, a humanity that is nowise the "possibility in being" (Levinas 1998b, p. 153), but is supporting of the other without any other choice: "(T)he psyche in the soul is the Other in me" (Levinas 1998b, p. 69).

Levinas utilizes the trope of maternity to signify this vulnerable subjectivity, which vividly shows the essential positivity of vulnerability. This positive image of vulnerable maternity can be seen from both the disturbance of a self-content subject, and also an ethical subjectivity that becomes "capable of fully human and fully ethical selfhood" (Rosato 2012, p. 350). First, through maternity and the inter-subjective relation that it signifies, Levinas argues against the identification of a subject as a position in a system or as self-consciousness. Rather, the oneself cannot establish her/himself; it is formed with the "absolute passivity" of the maternity (Levinas 1998b, p. 104). Maternity demonstrates that the attachment between the one and the other is made before the birth of the one, "an irreversible past" that cannot be cancelled by oneself. Maternity as moral vulnerability forbids the assumption that one could posit oneself for oneself (Levinas 1998b, p. 104). Thus, being moral cannot be a conscious choice, but is rather an involuntary relation with the other, a vulnerability for the other which is imprinted in humanity and born to each individual.

Meanwhile, maternity as one-for-the-other exemplifies an ethical subject being responsible for the others "to the point of substitution for the other", that is being responsible even for the other's responsibility. As Jennifer Rosato points out, the maternal ethical subjectivity in Levinas is not simply the bodily meaning of birth, which is not a normative principle either, but ethics in its concrete corporeal sense where the same suffers for the other on the level of sensibility (Rosato 2012). The image of "the groaning of the wounded entrails by those it will bear or has born" portraits maternity as unescapable suffering for the other to an ultimate level (Levinas 1998b, p. 75). It is exactly because of her capability to be vulnerable to suffer for the other, that maternity is "the highest possible situation for any person" (Rosato 2012, p. 350). This is to say, maternal vulnerability, rather than rationality or "in service of being" (Levinas 2000, p. 58), defines human beings whose humanity is shown in bearing others and being responsible for the other. To be fully human is to be able to be vulnerable to suffer for the other, that is, to "suffer for the worthiness and neediness of the other", where this suffering positively "empowers" the subject in the sense of informing his/her humanity (Kunz 1998, p. 109). Here we can see a subtle yet important difference between Levinasian vulnerability and vulnerability as embodiment. As we discussed previously, through their effort to redeem vulnerability, the feminist vulnerability theorists stress the importance of embodiment against the paternal tradition where bodily existence is seen as secondary. But for Levinas, incarnation or embodiment should be put into "a plot larger than" an attention given to the self (Levinas 1998b, p. 76). He argues, "I am bound to the other before being tied to my body" (Levinas 1998b, p. 76). This is to say, if the emphasis on embodiment is still a general care about the body, Levinas poses the question: whose body is it? If it is still the body of the self, the praised embodiment does not surpass a self-centered movement, which for Levinas is again to be criticized from an ethical perspective. It is problematic to propose a universalized and neutral embodiment while ignoring the fact that the discernment of whose body it is can lead to varied directions. Levinas reveals that the neutral notions are presupposed by an egology of the same where consciousness is my consciousness, truth rests on "self-sufficiency of the same", and free will is my will (Levinas 1969). Similarly, embodiment as my bodily existence leads to a discourse that begins 
from a care for individual conditions rather than inter-subjective relations. Although the vulnerability discourse aims at the betterment of society and promotes a political system dedicated to consolidation and responsiveness, it relies on a notion of vulnerability that presupposes the egoistic perspective would contradict itself.

This can especially be seen by comparing the current vulnerability theorists' notion of vulnerability with Levinas's notion of vulnerability. Firstly, when every human status as being vulnerable or autonomous is described from a prototype of an individual who is separated from his/her inter-human relationships and exists for him/herself, this discourse presupposes autonomy. It is an autonomy on the level of self-interestedness, beneath the phenomenon of autonomy of self-capability. This contrasts with the claim of inter-dependency. If inter-dependency is based upon a parallel self-interestedness, it is rather only a certain juxtaposing. Levinas's vulnerability is rather from the beginning the disinterested subject who is related to the other before establishing his/her identity. This subjectivity of vulnerability can lead to genuine inter-human relatedness beyond a relatedness via bodily dependency. Secondly, the calling for protection of vulnerability has as its destiny the eliminating of vulnerability, even though the possibility of full elimination is denied. In Levinas, vulnerability does not demand any elimination but is rather encouraged, as it produces the ethical subjectivity that is essential to humanity.

The difference between Levinasian vulnerability and vulnerability for the vulnerability theorists can lead to alternative political consequences, which, we will argue, address the very problems that the previous political discussions on vulnerability faced. For example, as we previously discussed, Fineman has directly engaged with the politicalized notion of vulnerability. She utilizes the conceptual tool of universal vulnerability to explore the necessity of the responsive state, that is the "monitoring institutions" and ensuring access to equal opportunities (Fineman 2013, p. 3). Yet her theory has faced difficulties, especially concerning its foundational presuppositions (Cloud 2013). Next, we will examine these difficulties and tentatively explore how Levinas's alternative perspective can help address them.

\section{A Tentative Exploration of the Alternative Political Signification of Vulnerability}

In his article "More than Utopia" Morgan Cloud compares Fineman's cause in pursuing a more responsive state of better equality through universal vulnerability with Thomas More's cause as expressed in his Utopia. He finds both of their causes to be types of reimaginations that aim at better institutional distributions of equality. Since Fineman writes in a time of liberal democracy, she could put forward unambiguous policy suggestions without any need to hide her ideas in fictions (Cloud 2013). Yet more importantly for our current discussion, Cloud makes two challenges to Fineman's theory. The first one is a common worry that the responsive state Fineman proposes must lead to "an autocratic state" (Cloud 2013, p. 89). For Cloud, Fineman does not have a substantive answer to this worry, but simply demands her readers imagine "the possibility of a non-authoritarian responsive state" (Cloud 2013, p. 91). Indeed, to rescue the traditional politics of its ignorance of vulnerability, Fineman gives the final call to institutions and the state, yet this can be a process of overpowering the state as well. If the solution to avoid this overpowering is all up to imagination, at least a direction for this imagination needs to be discussed.

Secondly, as Cloud also notes, one of the foundational presuppositions in Fineman's theory is her presumption about "human nature" (Cloud 2013). Cloud firstly revisits the debate on human nature found in More and argues against the view that as a utopianist, More is optimistic about human nature; rather, as reflected in the strict rules given by the state to each individual, Cloud maintains that More is a pessimist about human nature. Comparatively, Cloud deciphers the complexity in Fineman and shows the ambiguity in Fineman's stance. According to him, on one hand, Fineman seems to be pessimistic about human nature as she pursues the human ideal through institutional change rather than individual free choice. But on the other hand, Fineman believes in the public's imagination and a "people-driven" movement which will reform the institutions without overpowering the state (Cloud 2013, p. 92).This ambiguity shows a problematic facet of Fineman's theory. The self-interested individuals are believed to be able to be altruistic and to work on others' vulnerability. The tension 
exists when shared vulnerability is accepted as human nature, while the undercurrent of universal self-interestedness is not addressed.

Cloud pursues his critique by looking at the intention to re-emphasize autonomy and individual freedom (specifically freedom of possessions). For him, Fineman's claim about the universal nature of vulnerability, and particularly the cultivated status of autonomy, is not convincing. Cloud rather argues that, similar to vulnerability, the desire for independency and autonomy is also an important element of human nature. This can be seen in the problematic relationship between the notion of universality and particular in Fineman. Fineman argues that vulnerability is a universal human condition but that it is also demonstrated in the particular. This can in fact be said about the opposite conditions, independence and autonomy which according to Fineman are culturally diversified; however, one can claim that underneath these varied phenomena of autonomy and independence there might also be a universal human condition in its more abstract form. If Fineman ever wants her "utopia" of responsive states to become real, she needs to "incorporate our innate need for autonomy into her theory of interdependence based on vulnerability" (Cloud 2013, p. 94).

Based upon this debate, it is helpful to introduce Levinas's notion of vulnerability and his alternative perspective. When they propose a route to political transformation from the perspective of vulnerability and autonomy, the foundational element shared by both Cloud and Fineman is, as we mentioned before, a self-interested individual separated from his/her social relations. Levinas offers us a view on which the subjectivity of the subject is the vulnerability to responsibility for the other, which designates the firstness of an inter-human relation before any self-referred subject.

But one could be skeptical about Levinas's vulnerability and its social and political implications in real life. It seems much more utopian than both More and Fineman, as humanity is idealistically posited as one for the other without caring for one's own fate. Let us go back to the question and answer session after the lecture Levinas gave in Leyden: for the audience was not satisfied after listening to Levinas's clarification of his notion of vulnerability. The question that followed was:

And yet, when one suffers, when one lets evil come as it will, how can one be responsible? ...

Does the notion 'substitution' also offer some space for the idea that it is sometimes necessary to oppose the other for his good or for the good of the third party? (Levinas 1998a, p. 83)

Levinas answers with a further distinction between the subject in the form of " $\mathrm{I}$ " and in the form of "self moi". According to him, the "moi" will disappear when a generalized notion of "I" is established. When it is an "I", it is equal to the other's " $\mathrm{I}$ "; but to uncover the fact that the "I" is born from the "moi", one can save the "I" from losing him/herself in the totality. The generalized "I" can be said to be a non-authentic " $\mathrm{I}$ " in that in the generalization, the " $\mathrm{I}$ ", is designated by this generalization. Taking freedom as a test case, or the desire to own property in the argument developed by Cloud, the "I" can never receive real freedom or genuine possessions as a generalized term. What the "I" can or cannot get is already decided beforehand by this generalization. According to an example given by C. Fred Alford, the "I" is confined in his/her apartment which is given by the society and stays in without exposure to the other. This "I" who is put in his/her place is a prisoner within his/her own immanence. It is only when the "I" is open to the other and answers to the need of the other, that he/she could be a self again and free from this imprisonment (Alford 2004). This so-called investiture of freedom gives freedom its true meaning:

You feel small and insignificant, but not devalued, because your life now has a purpose, to serve the other. For the first time in your life you are free. Not to do what you want, but to put your very being into question, and so open yourself to the encounter with the other. (Alford 2004, p. 153)

To put Levinas's explanation on a broader social political level, we argue that to reveal the vulnerable moi can address the problem in politics where "the civil servant cannot see the tear of the other" (Levinas 1996). Alford is right to point out that, with his recognition of the presence of the third 
party and the necessity of politics to meet the demand of justice, Levinas's vocabulary about politics seems ordinary, not as extreme as that in his ethics. He discusses politics in the sense of justice, law, institutions, state, even violence. But his admitting the importance of a concrete political system does not mean that Levinas prioritizes it. Even though he admits its importance, Levinas is against idolizing the state. He maintains in an interview on ethics and politics that "a person is more holy than a land, even a holy land, since, faced with an affront made to a person, this holy land appears in its nakedness to be, but stone and wood" (Levinas 1996, p. 297). This is to say, Levinasian vulnerability does not cancel the political but disrupts the political with responsibility for the other.

This can be seen especially through a comparison with Fineman's solution to vulnerability: the responsive state which takes care of the shared vulnerability. From Levinas's perspective, the problems with this solution can be seen as the following: the responsive state needs to give order to redistribute for better equality. This can either become a repression or a political ambition. In both ways, this response from the state would be delivered in the form of "Cain-like coldness", as a form of transfer of sentiment (Alford 2004). But the Levinasian reconstruction of the political meaning of vulnerability will begin with each individual in their moi who does not lose their sense of responsibility in their political status. The question of justice to each citizen is not what I can get from a just state, but a disinterested question "what do I have to do with justice?" (Levinas 1998b, p. 159). Even though the current presence of a Levinasian state would be similar to any modern liberalism, the important thing is that his ethics already gives his politics a different foundation compared to the other political theories. And this different foundation perhaps will not change politics here and now; yet we would argue that the disruption brought to politics by vulnerability can change the direction of a movement or development of politics. Levinas's vulnerability could change the direction of where politics could go. More importantly, this change of direction will not be ontologically written down by any theorists. It is not a theoretical enforcement such as the one promoted by Fineman; instead, this change will happen when each individual hears the call from his/her vulnerable moi and realizes his/her responsibility for the other that disrupts their desire to be free or to possess excessive goods.

With this said, one should note that the state will still have its place even in the face of disruption from vulnerability. As Alford points out, the individual "needs to be fostered and protected so that he or she can dedicate himself or herself to the tears of the other" (Alford 2004, p. 168). The state needs to protect, even when the subject is facing his/her responsibility for the other. This is because, for both the third party and the other, their relation is beyond the grasp of the subject. Yet, a state that protects one's self-interested acts and a state that protects self-sacrificial acts are ultimately different. As for the latter, the responsive political system is not one that protects the vulnerable so that there will be less inequality, but one that provides a secure space for people who dare to be morally vulnerable, that is, to be the moi who dares to share my goods and time to reach out to help another. This can also be the difference between a liberal democracy that is ontologically stuck in itself, and the liberal democracy that pursues constant betterment of justice and a secure space for ethical relations. This betterment is not motivated by the ambition of the state to perfect itself, but by each individual's moral vulnerability, their being vulnerable to the surplus of responsibility for the others.

\section{Conclusions}

In this paper we have revisited the recent political discussions of vulnerability theorists and addressed the problem in their new account of the positivity of vulnerability, where the positivity is often posited as too functional. Drawing on the abstract yet provocative notion of vulnerability from Levinas, which is in contrast with the mainstream discussions, we show that Levinas's notion of vulnerability is essentially positive, as it defines an ethical subjectivity which for Levinas is precisely humanity. We hence looked into the political implications of this alternative notion of vulnerability. By engaging with Fineman and her critics, we reveal that the Levinasian political significance of vulnerability refuses to give any new ontological theorization of politics, but disrupts the indifference within the liberal system, which calls for betterment of justice through evoking each individual of 
their vulnerable self that bears responsibility for the other beyond any calculative political response. With the tentative exploration given in the current paper, we hope the alternative and obscure Levinasian discussions on vulnerability can contribute critically to the current vulnerability literature, especially politically.

Funding: This research received no external funding.

Acknowledgments: I'd like to thank Richard Cohen, Jolanta Saldukaityte and James McLachlan for their passionate teaching of Emmanuel Levinas's philosophy during the LPSS and my fellow seminar participants for deepening my understanding of Levinas. I want to thank the reviewers for their kind and very helpful comments on this paper and the editors from Religions for their aid and patience!

Conflicts of Interest: The author declares no conflict of interest.

\section{References}

Alcoff, Linda Martin. 2000. Phenomenology, Post-Structuralism, and Feminist Theory on the Concept of Experience. In Feminist Phenomenology. Dordrecht: Kluwer Academic Publishers.

Alford, C. Fr. 2004. Levinas and Political Theory. Political Theory 32: 146-71. [CrossRef]

Anderson, Pamela Sue. Forthcoming. Towards a New Philosophical Imaginary. Love and Vulnerability: Thinking with Pamela Sue Anderson. Special Issue of Angelaki: Journal of the Theoretical Humanities.

Bernasconi, Robert. 2002. What Is the Question to Which 'substitution' Is the Answer? In The Cambridge Companion to Levinas. Edited by Robert Bernasconi and Simon Critchley. Cambridge: Cambridge University Press, pp. 234-51.

Butler, Judith, Zeynep Gambetti, and Leticia Sabsay. 2016. Introduction. In Vulnerability in Resistance. Edited by Judith Butler, Zeynep Gambetti and Leticia Sabsay. Durham and London: Duke University Press.

Butler, Judith. 2016. Rethinking Vulnerability and Resistance. In Vulnerability in Resistance. Edited by Judith Butler, Zeynep Gambetti and Leticia Sabsay. Durham and London: Duke University Press, pp. 9-19.

Caygill, Howard. 2002. Levinas and the Political. London: Routledge.

Cloud, Morgan. 2013. More than Utopia. In Vulnerability: Reflections on a New Ethical Foundation for Law and Politics. Surrey: Ashgate Publishing Limited, pp. 77-95.

Cohen, Richard A. 2010. Levinasian Meditations: Ethics, Philosophy, and Religion. Pittsburgh: Duquesne University Press.

Fineman, Martha Albertson. 2008. The Vulnerable Subject: Anchoring Equality in the Human Condition. Yale Journal of Law and Feminism 20: 1-23.

Fineman, Martha Albertson. 2013. Equality, Autonomy and the Vulnerable Subject in Law and Politics. In Vulnerability: Reflections on a New Ethical Foundation for Law and Politics. Edited by Martha Albertson Fineman and Anna Grear. Surrey: Ashgate Publishing Limited, pp. 13-28.

Irigaray, Luce. 1991. Questions to Emmanuel Levinas. In Rereading Levinas. Edited by Simon Critchley and Robert Bernasconi. Bloomington: Indiana University Press.

Katz, Claire. 2007. Levinas between Agape and Eros. Symposium: Canadian Journal of Continental Philosophy 11: 333-50. [CrossRef]

Kunz, George. 1998. The Paradox of Power and Weakness: Levinas and an Alternative Paradigm for Psychology. Albany: State University of New York Press.

Levinas, Emmanuel. 1969. Totality and Infinity: An Essay on Exteriority. Translated by Alphonso Lingis. Pittsburgh: Duquesne University Press.

Levinas, Emmanuel. 1996. Emmanuel Levinas: Basic Philosophical Writings. Edited by Adriaan Peperzak, Simon Critchley and Robert Bernasconi. Bloomington: Indiana University Press.

Levinas, Emmanuel. 1998a. Of God Who Comes to Mind. Translated by Bettina Bergo. Stanford: Stanford University Press. Levinas, Emmanuel. 1998b. Otherwise than Being or Beyond Essence. Translated by Alphonso Lingis. Pittsburgh: Kluwer Academic Publishers.

Levinas, Emmanuel. 2000. God, Death and Time. Translated by Bettina Bergo. Stanford: Stanford University Press. Murphy, Ann. 2011. Corporeal Vulnerability and the New Humanism. Hypatia 26: 575-90. [CrossRef]

Morgan, Michael L. 2016. Levinas's Ethical Politics. Bloomington and Indianapolis: Indiana University Press. 
Rosato, Jennifer. 2012. Woman as Vulnerable Self: The Trope of Maternity in Levinas's 'Otherwise Than Being'. Hypatia 27: 348-65. [CrossRef]

Timmer, Alexandra. 2013. A Quiet Revolution: Vulnerability in the European Court of Human Rights. In Vulnerability: Reflections on a New Ethical Foundation for Law and Politics. Surrey: Ashgate Publishing Limited, pp. 147-70. 